\title{
Branded versus generic drug use in chronic disease management in Hong Kong- perspectives of health care professionals and the general public
}

\author{
Vivian WY Lee *, Franco WT Cheng, Felix YH Fong, Enoch EN Ng, Laadan LH Lo, Livia YS Ngai, \\ Amy SM Lam
}

\section{A B S T R A C T}

Introduction: The aim of the present study was to evaluate the understanding of generic substitution among health care professionals and members of the general public ("general public") in Hong Kong.

Methods: This cross-sectional descriptive study was performed by using a self-completed anonymous questionnaire from March 2015 to May 2017. The questionnaire included demographic data, knowledge of generic drugs, experiences of generic substitution, and views on policy.

Results: A total of 2106 general public, 73 doctors, 22 nurses, and 50 pharmacists responded the questionnaire. In all, $41.2 \%$ of the general public was aware that generic drugs have the same active ingredients. Although a majority of the health care professionals knew that generic drugs have the same active ingredients (doctors: 79.5\%; nurses: 86.4\%; pharmacists: $98.0 \%$ ), many were unaware of bioequivalence (doctors: $37.0 \%$; nurses: $18.2 \%$; pharmacists: 50.0\%). "Efficacy" was ranked as the primary concern among all groups; a substantial portion of respondents reported experiencing adverse drug reactions upon generic substitution (general public: 26.6\%; doctors: 23.3\%; nurses: 9.1\%; pharmacists: $42.0 \%)$. At least half of the that patients should be given a choice for generic substitution. However, fewer than one-fifth of doctors and nurses and approximately one-third of pharmacists considered that patient consent was needed prior to generic substitution, compared with approximately two-thirds of the general public.

Conclusion: The knowledge and perception of generic substitution remains low, both in the general public and among health care professionals. This knowledge deficit could potentially lead to different perspectives among stakeholders regarding generic substitution.

\section{Hong Kong Med J 2018;24:554-60 \\ DOI: $10.12809 / \mathrm{hkmj} 177087$}

VWY Lee *, PharmD

FWT Cheng, BPharm, MCP

FYH Fong, BPharm

EEN Ng, BA

LLH Lo, BA

LYS Ngai, BPharm

ASM Lam, BPharm

School of Pharmacy, The Chinese University of Hong Kong, Shatin, Hong Kong

* Corresponding author: vivianlee@cuhk.edu.hk

New knowledge added by this study

- Knowledge and perception of generic substitution remains low, both in the general public and among health care professionals.

- The general public, nurses, and pharmacists considered that patients should be given a choice for generic substitution.

- Fewer than one-fifth of doctors and nurses and approximately one-third of pharmacists believed that patient consent was needed prior to generic substitution, compared with approximately two-thirds of the general public.

Implications for clinical practice or policy

- Disagreements exist among stakeholders, although generic substitution is commonly employed in Hong Kong.

- A number of patients reported adverse drug reactions upon generic substitution, which may be clinically significant. Further investigation is warranted.

\section{Background}

Health care expenditures have been escalating in recent years and have thus become a global challenge. Generic substitution is an important approach for lessening health care expenditures. The use of generic drugs allows patients to use the same active ingredients, dosage form, strength, and route of administration, with a similar efficacy 
and safety, as well as a lower price than that of the branded product. ${ }^{1,2}$ It is estimated that the use of generic drugs reduces the overall cost of health care in Europe by $€ 100$ billion annually. ${ }^{3}$

In Hong Kong, drug expenditures comprised $10 \%$ of the total expenditures of the Hospital Authority, ${ }^{4}$ a statutory body managing all public hospitals and institutions in Hong Kong, in 2015. In addition, drug expenditures increased markedly by $15.4 \%$ from 2013 to $2015 .{ }^{4}$ Because the public health care system is heavily subsidised by the government, cost containment of drug expenditures is vital in public hospitals. Therefore, it is not uncommon to adopt generic substitution in public hospitals, although it is not legally required in Hong Kong.

Generic substitution, either voluntary or mandatory, has been introduced in many countries around the world. ${ }^{5,6}$ However, patients and health care professionals remain sceptical regarding the use of generic drugs, ${ }^{6-12}$ despite the lack of evidence for significant clinical risks. ${ }^{13-15}$ In Hong Kong, medicines are typically supplied in clinics or hospitals, because prescribing and dispensing are not separated. As a result, the prescribing and dispensing of generic drugs relies on the attending physicians and internal policies established by public hospitals. There are few choices for members of the general public ("general public"). Furthermore, only stability data are required for the registration of pharmaceutical products in Hong Kong, ${ }^{16}$ while pharmacokinetic studies are generally required in many other countries, such as the United States and New Zealand. ${ }^{17,18}$ In 2009, a review committee recommended the inclusion of bioavailability and bioequivalence (BABE) studies as requirements for registration of generic drugs, as well as phased implementation of these new requirements. As of 2016, Phase 2 requirements for BABE studies were implemented; BABE studies are now mandatory for 29 antiepileptic drugs and 38 drugs with narrow therapeutic ranges. ${ }^{19}$ However, the suitability for most generic substitutions, especially in terms of the bioequivalence of the products, remains questionable. Owing to the lack of pharmacokinetic data, uncertainty may have greater impact in cases of generic-to-generic substitution. Generic-togeneric substitution due to manufacturer-related interruptions in drug distribution is common in Hong Kong. ${ }^{4}$

The present study aimed to evaluate the understanding of generic substitution among health care professionals and the general public, and to identify their experiences in terms of undesirable clinical outcomes after substitution.

\section{Methods}

A cross-sectional descriptive study was conducted from March 2015 to May 2017 by using a self-

\section{醫護界與大眾對於使用 $「$ 專利藥物」與 $「$ 非專利 藥物」之意見調查 \\ 李詠恩、鄭永德、方恩衍、吳以諾、盧樂謙、倪綺珊、林淑敏}

引言：研究旨在探討香港醫護界及病患對於「非專利藥物」之認識。

方法：這項橫斷面描述性研究於2015年3月至2017年5月期間，以自 我完成的匿名問卷進行。問卷內容包括人口統計學數據、對「非專利 藥物」的認識、使用「非專利藥物」的經驗和對政策的觀點。

結果：共有2106名市民、73名醫生、22名護士及50名藥劑師參與是 次研究。當中 $41.2 \%$ 市民知道「非專利藥物」與「專利藥物」的有相 同的有效成份。雖然大部份醫護人員（包括 $79.5 \%$ 醫生、 $86.4 \%$ 護士 和 $98.0 \%$ 藥劑師 ) 亦知道「非專利藥物」與「專利藥物」的有相同 的有效成份, 但很多也不清楚「生物等效性」的定義（包括 $37.0 \%$ 醫 生、 $18.2 \%$ 護士和 $50.0 \%$ 藥劑師 ）。四組參與者均認為「藥效」是決 定是否使用「非專利藥物」的最重要因素, 而各組參與者均指出曾因 使用「非專利藥物」出現不良藥物反應（包括 $26.6 \%$ 市民、 $23.3 \%$ 醫 生、 $9.1 \%$ 護士和 $42.0 \%$ 藥劑師 ) 。超過半數受訪市民、護士及藥劑師 認為病人有權選擇是否選用「非專利藥物」。相比約三份之二受訪市 民認為應先取得病人同意方能使用「非專利藥物」, 此項只獲約五分 之一醫生、護士及三分之一藥劑師同意。

結論：醫護人員及市民對於「非專利藥物」的認識和認知不足，或會 造成各方持份者對「非專利藥物」使用的觀點出現分歧。

completed anonymous questionnaire in Hong Kong. No consent was obtained because the questionnaire was conducted in an anonymous manner. The private information collected was considered non-sensitive and participants were informed that precautions would be taken to preserve the confidentiality of the research data. The background and aims of the questionnaire were disclosed to participants before they completed the questionnaire.

Two sets of questionnaires were developed for the general public and health care professionals, respectively. Both questionnaires cover four areas, including the demographic data of the interviewees (age, gender, monthly income, level of education, chronic diseases and insurance), knowledge and perception of generic drugs, experiences of generic substitution, and policy views for generic substitution. To ascertain the overall reliability of the results of the questionnaire, it was further modified in accordance with feedback from a pilot study that involved 50 physicians and 500 patients during January to February 2015.

Five statements, regarding active ingredient, dosage form, efficacy, similarity to branded drugs, price and quality, were used to assess knowledge regarding generic drugs in the general public; four separate statements, regarding active ingredient, strength, dosage form, and excipient, were used to assess knowledge among health care professionals. Health care professionals were further asked about 
the legal requirements for registration of generic drugs in Hong Kong, the definition of bioequivalence, and their perceptions of generic drugs. A 5-point Likert scale was used to assess perceptions of generic drugs with regard to price, side-effect profile, quality, efficacy, and preferences for using branded drugs.

In the third part of the questionnaires, experiences of using generic drugs were assessed. These included adverse drug reactions encountered after switching from branded to generic products, as well as factors that affected the use of generic drugs compared with branded drugs. The questionnaire for the general public further assessed previous usage of generic drugs, previous experience of switching from branded to generic, and the respondents' willingness-to-pay for branded products. Respondents' preferences regarding branded or generic products, with respect to changes in the price of branded products, were documented; the hypothetical price decreased from $200 \%$ of the generic price to equivalent to the price of generic products, in intervals of $20 \%$ reductions. Only respondents with chronic illnesses were included in this portion of the analysis, as this population is more sensitive to changes in drug price.

The last portion of the questionnaire assessed views regarding the need to obtain patients' consent for substitution of branded products with generic products. The general public was further queried whether notification and explanation were required upon generic substitution.

The questionnaire for the general public was distributed during an outreach programme and public lecture series organised by the School of Pharmacy, The Chinese University of Hong Kong. Physicians from public sectors were recruited from the Prince of Wales Hospital; private physicians were randomly identified and recruited from the list of the Hong Kong Doctor Association, accessed via http://www.hkdoctors.org. Questionnaires were distributed via email to pharmacists and nurses who had participated in outreach programmes organised by the School of Pharmacy, The Chinese University of Hong Kong since 2010.

Discrete data were presented as frequency percentages; mean 5-point Likert scale ratings were used. Cumulative frequency was employed to determine the rank order of factors that affected the use of generic drugs. All data were analysed using Excel 2017 (Microsoft Corp., Redmond [WA], United States).

\section{Results}

A total of 5748 individuals were invited to complete the questionnaire, and 2251 complete responses were received. Tables 1 and 2 summarise the demographic data of the 2106 general public respondents, 73 doctor respondents, 22 nurse respondents, and 50 pharmacist respondents.

Only $41.2 \%$ and $23.4 \%$ of the general public respondents were aware that generic drugs have the same active ingredients and dosage forms, respectively, as branded drugs. However, 65.5\% of the respondents thought generic drugs were cheaper; only $14.9 \%$ believed that they were of lower

TABLE I. Summary of respondents' demographic data*

\begin{tabular}{|c|c|c|c|c|}
\hline & General public $(n=2106)$ & Doctors $(n=73)$ & Nurses (n=22) & Pharmacists $(n=50)$ \\
\hline Male sex & $738(35.0)$ & $47(64.4)$ & $4(18.2)$ & $21(42.0)$ \\
\hline \multicolumn{5}{|l|}{ Age-group (years) } \\
\hline $18-25$ & $536(25.5)$ & 0 & 7 (31.8) & $25(50.0)$ \\
\hline $26-35$ & $293(13.9)$ & $15(20.5)$ & $14(63.6)$ & $25(50.0)$ \\
\hline $36-45$ & $254(12.1)$ & $29(39.7)$ & $1(4.5)$ & 0 \\
\hline $46-55$ & $313(14.9)$ & $17(23.3)$ & 0 & 0 \\
\hline $56-65$ & $358(17.0)$ & $8(11.0)$ & 0 & 0 \\
\hline$>65$ & $320(15.2)$ & $4(5.5)$ & 0 & 0 \\
\hline Not specified & $32(1.5)$ & 0 & 0 & 0 \\
\hline \multicolumn{5}{|l|}{ Workplace } \\
\hline Public hospital & $\mathrm{N} / \mathrm{A}$ & $23(31.5)$ & $13(59.1)$ & $15(30.0)$ \\
\hline Private hospital/clinic & $\mathrm{N} / \mathrm{A}$ & $50(68.5)$ & $3(13.6)$ & $11(22.0)$ \\
\hline Community & $\mathrm{N} / \mathrm{A}$ & 0 & $1(4.5)$ & $13(26.0)$ \\
\hline Pharmaceutical company & $\mathrm{N} / \mathrm{A}$ & 0 & 0 & $7(14.0)$ \\
\hline Other & $\mathrm{N} / \mathrm{A}$ & 0 & $5(22.7)$ & $4(8.0)$ \\
\hline
\end{tabular}

Abbreviation: N/A = not applicable

* Data are shown as No. (\%) of respondents 
TABLE 2. Summary of demographic data of general public respondents $(n=2106)$

\begin{tabular}{|c|c|}
\hline & $\begin{array}{l}\text { No. }(\%) \text { of } \\
\text { respondents }\end{array}$ \\
\hline \multicolumn{2}{|l|}{ Monthly income (HKD) } \\
\hline$<8000$ & $892(42.4)$ \\
\hline $8001-13000$ & $178(8.5)$ \\
\hline $13001-18000$ & 237 (11.3) \\
\hline $18001-23000$ & $189(9.0)$ \\
\hline $23001-28000$ & $131(6.2)$ \\
\hline $28001-33000$ & $102(4.8)$ \\
\hline$>33000$ & $222(10.5)$ \\
\hline Not disclosed & $155(7.4)$ \\
\hline \multicolumn{2}{|l|}{ Level of education } \\
\hline None completed & $56(2.7)$ \\
\hline Primary & $188(8.9)$ \\
\hline Secondary & $649(30.8)$ \\
\hline Tertiary or higher & $1194(56.7)$ \\
\hline Not disclosed & $19(0.9)$ \\
\hline With chronic diseases & $884(42.0)$ \\
\hline With medical insurance & $1007(47.8)$ \\
\hline \multicolumn{2}{|l|}{ Sources of drugs } \\
\hline Public hospitals & $477(22.6)$ \\
\hline Private hospitals & $91(4.3)$ \\
\hline Clinics by Jockey Club & $163(7.7)$ \\
\hline Private clinics & $879(41.7)$ \\
\hline \multicolumn{2}{|l|}{ Monthly drug expenditures (HKD) } \\
\hline$<100$ & $1376(65.3)$ \\
\hline $101-500$ & $476(22.6)$ \\
\hline $501-1000$ & $101(4.8)$ \\
\hline$>1001$ & $36(1.7)$ \\
\hline Not disclosed & $117(5.6)$ \\
\hline Knew the term "branded drugs" & $951(45.2)$ \\
\hline \multicolumn{2}{|l|}{ Experience of using generic drugs } \\
\hline Yes & $618(29.3)$ \\
\hline No & $268(12.7)$ \\
\hline I do not know & $1102(52.3)$ \\
\hline Not answered & $118(5.6)$ \\
\hline \multicolumn{2}{|c|}{ Experience of generic drug substitution } \\
\hline Yes & $229(10.9)$ \\
\hline No & $647(30.7)$ \\
\hline I do not know & $1121(53.2)$ \\
\hline Not answered & 109 (5.2) \\
\hline
\end{tabular}

quality. In contrast, the majority of the health care professionals were aware that generic drugs have the same active ingredients (doctors: 79.5\%; nurses: 86.4\%; pharmacists: $98.0 \%$ ) and strength (doctors:
69.9\%; nurses: 54.5\%; pharmacists: $90.0 \%)$ as the branded product at a cheaper price (doctors: $74.0 \%$; nurses: 54.5\%; pharmacists: 98.0\%). However, they were not aware of the definition of bioequivalence (doctors: $37.0 \%$; nurses: $18.2 \%$; pharmacists: $50.0 \%$ ). Table 3 summarises the knowledge and perceptions of generic drugs among the different groups of respondents.

All four groups of respondents ranked "efficacy" as their primary concern when considering generic substitution. Other factors that were considered are detailed in Table 4. Moreover, a substantial number of respondents reported that they or their patients experienced adverse drug reactions upon generic substitution (general public: $26.6 \%$; doctors: 23.3\%; nurses: $9.1 \%$; pharmacists: $42.0 \%$ ), primarily comprising cardiovascular, gastrointestinal, psychiatric, and respiratory medications. The preferences of patients with chronic illnesses for branded products are illustrated in the Figure. Most respondents would opt for branded products as long as the price was not more than 1.4-times that of generic products.

At least half of the general public (50.0\%) and health care professionals (nurses: 63.6\%; pharmacists: 92.0\%), except doctors (42.5\%), considered that patients should be given a choice for generic substitution. However, fewer than one-fifth of doctors and nurses, and approximately one-third of pharmacists, considered that patient consent was necessary prior to generic substitution, compared with approximately two-thirds of the general public. Views regarding policies of generic substitution among the different stakeholders are listed in Table 5 .

\section{Discussion}

A Japanese study showed that most patient respondents declined the use of generic drugs. ${ }^{6}$ In contrast to that report, the current study showed that $53.2 \%$ of the general public in Hong Kong was unaware whether they were using branded medications or generic substitutes. The proportion of awareness of "branded drugs" was also significantly lower in the current study than in the Japanese study (45.2\% vs $68.4 \%){ }^{6}$ This difference could be attributed to the lower literacy in Hong Kong. More than $40 \%$ of respondents did not attend tertiary school or higher education, and more than $10 \%$ only completed primary school or lower. This low level of literacy may act as a barrier against effective communication when discussing the use of generic substitutes.

From our findings, generic substitution remains controversial in Hong Kong. Although most general public respondents believed that generic substitutes are not of lower quality, they demanded notification from health care professionals and 
TABLE 3. Knowledge and perception of generic drugs*

\begin{tabular}{|c|c|c|c|c|}
\hline & $\begin{array}{l}\text { General public } \\
(n=2106)\end{array}$ & Doctors ( $n=73$ ) & Nurses $(n=22)$ & $\begin{array}{l}\text { Pharmacists } \\
(n=50)\end{array}$ \\
\hline Identical active ingredients & $867(41.2)$ & $58(79.5)$ & $19(86.4)$ & $49(98.0)$ \\
\hline Identical strength & $\mathrm{N} / \mathrm{A}$ & $51(69.9)$ & $12(54.5)$ & $45(90.0)$ \\
\hline Identical dosage form & $493(23.4)$ & $53(72.6)$ & $10(45.5)$ & $43(86.0)$ \\
\hline Different excipients & $\mathrm{N} / \mathrm{A}$ & $22(30.1)$ & $11(50.0)$ & $45(90.0)$ \\
\hline Aware of the definition of bioequivalence & N/A & $27(37.0)$ & $4(18.2)$ & $25(50.0)$ \\
\hline $\begin{array}{l}\text { Aware of the legal documentation required for registration of } \\
\text { generic products }\end{array}$ & N/A & $22(30.1)$ & $13(59.1)$ & $36(72.0)$ \\
\hline Cheaper & $1379(65.5)$ & $54(74.0)$ & $12(54.5)$ & $49(98.0)$ \\
\hline Lower quality & $314(14.9)$ & $28(38.4)$ & $10(45.5)$ & $25(50.0)$ \\
\hline \multicolumn{5}{|l|}{$\begin{array}{l}\text { Perception of generic drugs using a } 5 \text {-point Likert scale (health care } \\
\text { professionals only) }(1=\text { strongly disagree and } 5=\text { strongly agree) }\end{array}$} \\
\hline Generic drugs are cheaper & $\mathrm{N} / \mathrm{A}$ & 4.1 & 3.2 & 4.6 \\
\hline Generic drugs cause more side-effects & N/A & 2.9 & 2.5 & 2.5 \\
\hline Generic drugs have lower quality than branded products & N/A & 3.2 & 3.2 & 3.3 \\
\hline Branded drugs demonstrate better efficacy & N/A & 3.3 & 3.1 & 3.1 \\
\hline I prefer recommending branded products over generic products & $\mathrm{N} / \mathrm{A}$ & 3.2 & 3.3 & 3.1 \\
\hline
\end{tabular}

Abbreviation: $\mathrm{N} / \mathrm{A}=$ not applicable

* Data are shown as No. (\%) of respondents

TABLE 4. Experiences of using generic drugs

\begin{tabular}{|c|c|c|c|c|}
\hline & $\begin{array}{l}\text { General public } \\
(n=2106)\end{array}$ & Doctors $(n=73)$ & Nurses $(n=22)$ & $\begin{array}{l}\text { Pharmacists } \\
\quad(n=50)\end{array}$ \\
\hline \multicolumn{5}{|c|}{$\begin{array}{l}\text { Factors affecting a switch between branded and generic drugs } \\
(1=\text { most important })^{\star}\end{array}$} \\
\hline Price & $4(96.0 \%)$ & $3(62.7 \%)$ & $3(68.2 \%)$ & $2(46.0 \%)$ \\
\hline Efficacy & $1(42.4 \%)$ & $1(59.3 \%)$ & $1(54.5 \%)$ & $1(46.0 \%)$ \\
\hline Origin & $5(70.1 \%)$ & $6(100.0 \%)$ & $4(59.1 \%)$ & $5(68.0 \%)$ \\
\hline Side-effect profile & $3(75.3 \%)$ & $2(50.8 \%)$ & $2(40.9 \%)$ & $3(58.0 \%)$ \\
\hline Patient preference & N/A & $5(69.5 \%)$ & $5(72.7 \%)$ & $4(58.0 \%)$ \\
\hline Health care professional recommendation & $2(49.0 \%)$ & N/A & N/A & N/A \\
\hline Brand & $6(100.0 \%)$ & $4(47.5 \%)$ & $6(100.0 \%)$ & $6(100.0 \%)$ \\
\hline Experienced ADR upon substitution & $61 / 229(26.6 \%)$ & 17 (23.3\%) & $2(9.1 \%)$ & $21(42.0 \%)$ \\
\hline
\end{tabular}

Abbreviations: $A D R=$ adverse drug reaction; N/A = not applicable

* Figures in brackets indicate cumulative percentages of the ranks

TABLE 5. Views regarding policies for generic substitution*

\begin{tabular}{|c|c|c|c|c|}
\hline & $\begin{array}{l}\text { General public } \\
(n=2106)\end{array}$ & Doctors $(n=73)$ & Nurses $(n=22)$ & $\begin{array}{l}\text { Pharmacists } \\
\qquad(\mathrm{n}=50)\end{array}$ \\
\hline Patients have discretion to choose branded or generic product & $1052(50.0)$ & $31(42.5)$ & $14(63.6)$ & $46(92.0)$ \\
\hline $\begin{array}{l}\text { Patient consent is required prior to substitution in hospital } \\
\text { pharmacy }\end{array}$ & $1456(69.1)$ & $8(11.0)$ & $4(18.2)$ & $17(34.0)$ \\
\hline Patients must be notified on substitution & $1805(85.7)$ & $\mathrm{N} / \mathrm{A}$ & $\mathrm{N} / \mathrm{A}$ & $\mathrm{N} / \mathrm{A}$ \\
\hline Patients must be given an explanation on substitution & $1813(86.1)$ & $\mathrm{N} / \mathrm{A}$ & $\mathrm{N} / \mathrm{A}$ & $\mathrm{N} / \mathrm{A}$ \\
\hline
\end{tabular}

Abbreviation: N/A = not applicable

* Data are shown as No. (\%) of respondents agreeing with each statement 
wished to be given the option to consent to generic substitution; most health care professionals were reluctant to follow this approach. The reluctance may be attributed to the lack of understanding about generic drugs. Indeed, most doctors, nurses, and pharmacists tended to believe that generic drugs were less expensive because of their lower quality. Thus, it is unsurprising that the health care professionals exhibited a slight tendency to recommend branded products over generic substitutes (5-point Likert scale score $=3.1-3.3)$. Hence, education combined with more stringent registration requirements (eg, mandatory pharmacokinetic data) is essential for greater acceptance of generic drugs and maintenance of a sustainable health care system.

Despite being ranked as a primary concern regarding generic substitution, the efficacy of generic drugs cannot be guaranteed in Hong Kong due to a lack of pharmacokinetic data. Indeed, over $40 \%$ of the health care professional respondents stated that generic medications were of lower quality. Very recently, the Hong Kong government began to include BABE studies as legal requirements for the registration of certain generic drugs (eg, antiepileptic drugs and drugs with narrow therapeutic ranges), in addition to existing good manufacturing practice requirements. ${ }^{16}$ With the implementation of BABE requirements, this fundamental step may support increased quality of generic products, thus addressing the concerns of both the general public and health care professionals. ${ }^{20}$

Adverse drug reactions were also encountered upon generic substitution among various categories of commonly prescribed medications. Similar results have been reported in a Norway study, in which approximately one-third of patients reported negative experiences upon switching; there was no correlation between the adverse reaction and age, gender, or complexity of medical regimen. ${ }^{10}$ The lack of BABE studies could be a possible explanation, but further investigation is warranted.

Concerning preferences for branded products with respect to changes in price, it was surprising that not all respondents opted for branded products, even when the price was identical to that of generic products. Furthermore, the preference for branded products did not linearly increase with price. These results could be attributed to the design of the questionnaire and to the perceptions of the respondents, because the questionnaire did not specify the nature of the hypothetical medications that were substituted (eg, short-term or long-term administration), the equivalence of the products, or the actual price of the products. These factors may be significant to respondents when making a decision.

As indicated by the low response rate, selection bias is a major limitation of the current study due to its self-administered questionnaire

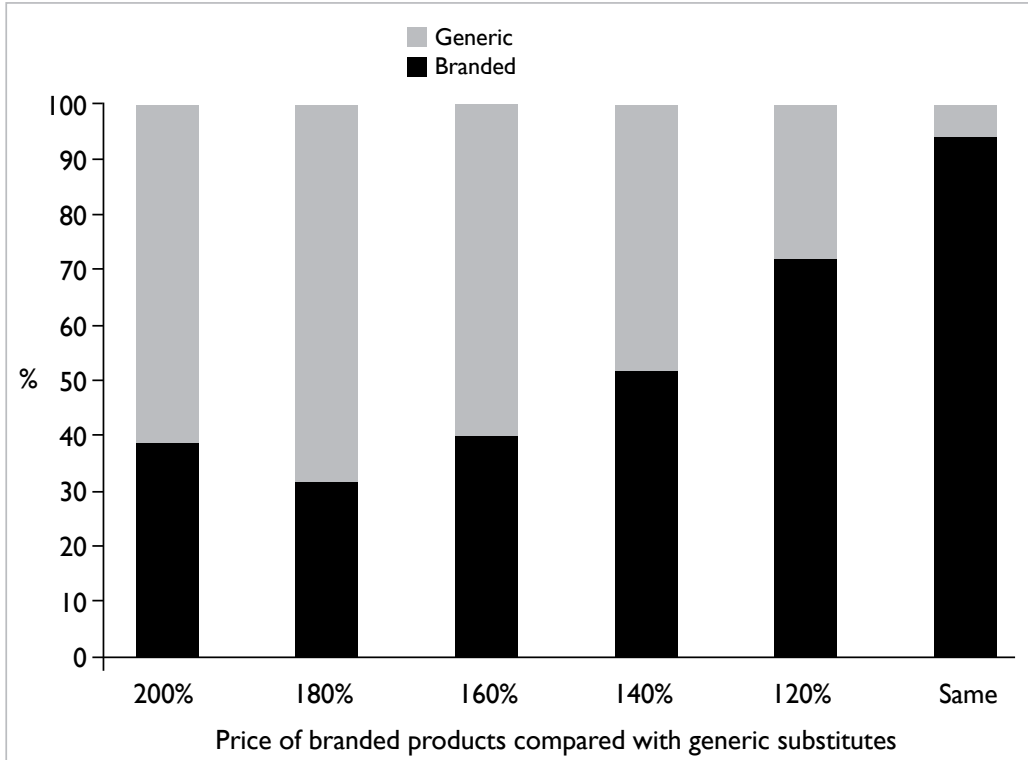

FIG. Preferences for branded products with changes in price

nature and the convenient sampling method used to distribute the questionnaire. The unexpected high proportion of respondents with tertiary education or higher may be explained by an increased level of health consciousness among individuals who attend outreach services and public lectures organised by the university, as well as the complexity of the questionnaire. The survey results in this study potentially overestimated the knowledge of the general public with respect to generic drugs; thus, the generalisability of the results to the whole population may be limited. Further, as indicated from the demographic data, the sample size of health care professionals was relatively small and may not be representative of the overall population of health care professionals.

\section{Conclusion}

Although generic medications have been commonly used in Hong Kong, knowledge and perception of these medications has remained low, both in the general public and among health care professionals. This knowledge deficit could potentially lead to conflicting perspectives among stakeholders in terms of "generic substitution."

\section{Author contributions}

Concept and design of study: VWY Lee.

Acquisition, analysis, and interpretation of data: FYH Fong, EEN Ng, LLH Lo, LYS Ngai, ASM Lam.

Drafting of the article: FWT Cheng.

Critical revision of important intellectual content: VWY Lee, FWT Cheng. 


\section{Funding/support}

This research received no specific grant from any funding agency in the public, commercial, or not-for-profit sectors.

\section{Declaration}

The authors have no conflicts of interest to disclose. The authors had full access to the data, contributed to the study, approved the final version for publication, and take responsibility for its accuracy and integrity.

\section{Ethical approval}

This study was approved by the Survey and Behavioural Research Ethics of The Chinese University of Hong Kong and followed the Standards for Reporting Qualitative Research guidelines.

\section{References}

1. Center for Drug Evaluation and Research, US Food and Drug Administration. Facts About Generic Drugs. Available from: https://www.fda.gov/downloads/drugs/ resourcesforyou/consumers/buyingusingmedicinesafely/ understandinggenericdrugs/ucm305908.PDF. Accessed 25 Aug 2017.

2. King DR, Kanavos P. Encouraging the use of generic medicines: implications for transition economies. Croat Med J 2002;43:462-9.

3. Medicines for Europe. Our 5 pillars. Available from: http:// www.medicinesforeurope.com/generic-medicines/our-5pillars/. Accessed 25 Aug 2017.

4. Audit Commission, Hong Kong SAR Government. Report No. 67, Chapter 5, Hospital Authority's Drug Management. 2016. Available from: http://www.aud.gov.hk/pdf_e/ e67ch05.pdf. Accessed 3 Oct 2017.

5. Chong CP, March G, Clark A, Gilbert A, Hassali MA, Bahar $\mathrm{MB}$. A nationwide study on generic medicines substitution practices of Australian community pharmacists and patient acceptance. Health Policy 2011;99:139-48.

6. Kobayashi E, Karigome H, Sakurada T, Satoh N, Ueda S Patients' attitudes towards generic drug substitution in Japan. Health Policy 2011;99:60-5.

7. Andersson K, Sonesson C, Petzold M, Carlsten A, Lönnroth $\mathrm{K}$. What are the obstacles to generic substitution? An assessment of the behaviour of prescribers, patients and pharmacies during the first year of generic substitution in Sweden. Pharmacoepidemiol Drug Saf 2005;14:341-8.

8. Himmel W, Simmenroth-Nayda A, Niebling W, et al. What do primary care patients think about generic drugs? Int I Clin Pharmacol Ther 2005;43:472-9.

9. Iosifescu A, Halm EA, McGinn T, Siu AL, Federman AD. Beliefs about generic drugs among elderly adults in hospital-based primary care practices. Patient Educ Couns
2008;73:377-83.

10. Kjoenniksen I, Lindbaek M, Granas AG. Patients' attitudes towards and experiences of generic drug substitution in Norway. Pharm World Sci 2006;28:284-9.

11. Babar ZU, Grover P, Stewart J, et al. Evaluating pharmacists' views, knowledge, and perception regarding generic medicines in New Zealand. Res Social Adm Pharm 2011;7:294-305

12. Rodríguez-Calvillo JA, Lana A, Cueto A, Markham WA, López ML. Psychosocial factors associated with the prescription of generic drugs. Health Policy 2011;101:17884

13. Privitera MD, Welty TE, Gidal BE, et al. Generic-togeneric lamotrigine switches in people with epilepsy: the randomised controlled EQUIGEN trial. Lancet Neurol 2016;15:365-72.

14. Ting TY, Jiang W, Lionberger R, et al. Generic lamotrigine versus brand-name Lamictal bioequivalence in patients with epilepsy: A field test of the FDA bioequivalence standard. Epilepsia 2015;56:1415-24.

15. Williamson IJ, Reid A, Monie RD, Fennerty AG, Rimmer EM. Generic inhaled salbutamol versus branded salbutamol. A randomised double-blind study. Postgrad Med J 1997;73:156-8.

16. Food and Health Bureau, Hong Kong SAR Government. Report of the Review Committee on Regulation of Pharmaceutical Products in Hong Kong. 2009. http:// www.fhb.gov.hk/download/press_and_publications/ otherinfo/100105_pharm_review/en_full_report.pdf. Accessed 25 Aug 2017.

17. Guidance for Industry. Bioavailability and Bioequivalence Studies for Orally Administered Drug Products-General Considerations. US Department of Health and Human Services, Food and Drug Administration, Center for Drug Evaluation and Research; 2003.

18. New Zealand Medicines and Medical Devices Safety Authority. New Zealand regulatory guidelines for medicines. Part A: when is an application for approval of a new or changed medicine required? 2014. Available from: http://www.medsafe.govt.nz/regulatory/Guideline/ Full\%20-\%20NZ\%20Regulatory\%20Guidelines\%20for\%20 Medicines.pdf. Accessed 3 Oct 2017.

19. Pharmacy and Poisons Board Hong Kong. Implementation plan of Phase 2 requirement of bioavailability and bioequivalence studies for the registration of generic drugs. 2016. Available from: http://drugoffice.gov.hk/eps/ upload/eps_news/26420/EN/1/Letter\%20to\%20Trade\%20 -\%20Implementation\%20Plan\%20of\%20Phase\%202\%20 Requirement_v.5.pdf Accessed 25 Aug 2017.

20. Chua GN, Hassali MA, Shafie AA, Awaisu A. A survey exploring knowledge and perceptions of general practitioners towards the use of generic medicines in the northern state of Malaysia. Health Policy 2010;95:229-35. 